\title{
Stereotypies, compulsions, and normal behavior in the context of motor routines in the rock hyrax (Procavia capensis)
}

\author{
DANIEL SERRUYA and DAVID EILAM \\ Tel-Aviv University, Ramat-Aviv, Israel
}

\begin{abstract}
In the present study, we propose that the level of activity and organization in time and in space are the common link between motor routines in normal behavior, stereotypies, and compulsions. Specifically, an increase in activity, a shrinkage of the attended space, or an extension of time results in repetitive performance. This hypothesis is based on a discussion of stereotypies and compulsions in the context of motor routines in undisturbed behavior of the rock hyrax. Observations of hyraxes in the wild and in captivity revealed that their behavior constitutes motor routines at several levels of organization: (1) Activity is concentrated in a relatively limited region-a bush and an adjacent rocky ramp; (2) in both morning and afternoon, the hyraxes ascend the external branches of the bush, which they then leave in order to forage; (3) moving from the bush to the ramp and vice versa occurs along certain fixed routes; (4) while on the ramp, hyraxes tend to stop frequently on only certain fixed stones; (5) each such "preferred stone" has a typical location and directions of approach and departure; and (6) motor performance on the "preferred" stones typically involves crouching or sitting in certain typical postures, and is preceded and followed by only a few (if any) lateral movements. We propose that these recurrent behavioral patterns may constitute the normal foundation from which a reminiscent rigid motor performance that characterizes stereotypy and compulsive behavior develops.
\end{abstract}

Description of the spatiotemporal structure of motor routines dominated the early study of behavior, such as the head-down, tail-up of male sticklebacks (Tinbergen, 1951) or the incitement movement of female geese (Lorenz, 1971), which were described in the context of performance (chronological and/or temporal order) in reference to a threat, and were classified as innate instinctive behavior. Counterpart descriptions put forward the organization of noninherited behavior of individuals in the $l o$ cale space. In these studies, "habits" were considered as performance of fixed behaviors at fixed places (e.g., "Habit Ritual and Magic," Lorenz, 1966, p. 47; "the familiar path," von Uexkull, 1957, p. 50). Indeed, habits are a cardinal constituent of behavior; thus in some contexts the term habit is used more or less in the same sense as "behavior" or "behavior pattern" (Immelmann \& Beer, 1989). Whereas the term habit typically refers to acts that are "executed blindly and without reference to conse-

We are grateful to $G$. Mason, $H$. Szechtman, and several anonymous reviewers for their critical comments; Y. Benjamini for statistical advisory; P. Rudich for assistance in videotaping and analyses; $C$. Zeira for drawing Figure 4; G. Sheffer for general assistance; N. Paz for editing the manuscript; the zookeepers of the Meir Segal Center for Ecological Zoology in Tel-Aviv University for maintenance of the hyraxes; and the workers of the Nature Reserve Authority in Israel for approval and help in the fieldwork. This study was supported by the Israel Institute for Psychobiology, Charles E. Smith Foundation, Grant 10-96. Correspondence should be addressed to D. Eilam, Department of Zoology, Tel-Aviv University, Ramat-Aviv 69978, Israel (e-mail: eilam@) cesg.tau.ac.il). quences or appropriateness" (Legge \& Barker, 1976), the term motor routine is confined to predictable or unvarying performance of a specific act, the consequences or appropriateness of which may or may not be obvious. In the present study, we examined the extent to which the flow of daily activity is composed of fixed motor routines.

Spatial organization of motor behavior is traditionally assessed in two domains: (1) motor routines that are executed in particular places without progressing in the environment, and (2) progression along routes that connect these particular places (Eilam, 1987; Eilam \& Golani, 1989, 1994; Hediger, 1964). At the broader level of spatial organization, home range, territory, and other forms of living area (Hediger, 1964; Hoeck, Klein, \& Hoeck, 1982; Immelmann \& Beer, 1989) are probably the most familiar invariants in the spatial routines of animal movement. In the living range, there are particular places where typical behavioral patterns are carried out. For instance, black rhinos (Dicerus bicornis) crouch in fixed resting and sleeping locales in a fixed behavioral routine (Schenkel \& Schenkel-Hulliger, 1969). Demarcation is another behavioral routine that is typically displayed in particular places by many species (e.g., the hyena and the panda, Gorman \& Trowbridge, 1989; the otter, RoweRowe, 1992; and the black rhino, Schenkel \& SchenkelHulliger, 1969).

It is generally thought that habits or fixed motor routines in normal behavior have functional significance even though the nature of this significance is not clearly understood. Motor routines in pathological behavior, by 
contrast, are typically interpreted as "purposeless." Nonetheless, the perseverative performance of the fixed motor rituals in specific places by rats under chronic injections of the D2 dopamine agonist quinpirole (Eilam \& Golani, 1994; Szechtman, Talangbayan, Canaran, Dai, \& Eilam, 1994), as well as the inflated performance of acts by humans suffering from obsessive-compulsive disorders ( $\mathrm{Ra}-$ poport, 1989), is reminiscent of motor rituals observed in normal behavior.

In the present study, we describe the daily behavior of a colony of rock hyraxes (Procavia capensis) over the course of 1 year in order to determine whether the behavior of individual hyraxes constitutes fixed motor routines. For this purpose, we followed the behavior of marked individuals from onset of activity in the morning until they returned to their shelter at dusk. Behavior was inspected at the broader level of organization of behavior in the environment (e.g., stopping places, foraging sites, the directions of approach to or withdrawal from specific places) and also at the level of the sequence of movements performed by an individual animal in a specific place. We reasoned that such analysis might reveal the relative degrees of invariability that characterize behavior at the different levels of organization.

\section{METHOD}

\section{Subjects}

The rock hyrax (Procavia capensis) is a 2- to 3-kg herbivorous mammal that inhabits rocky habitats (Mendelssohn \& Yom-Tov, 1987). Hyraxes were chosen for the present study because they are diurnal and social animals that tend to move on exposed rocky mountain slopes. These characteristics enabled relatively easy observation and videotaping of the hyrax colonies.

\section{Setting}

Hyraxes were observed from a hide at two sites: a natural habitat in the Judean desert and a cage at the Meir Segal Garden for Zoological Research. The natural habitat was a group of rocky ramps at the border of the En-Gedi conservation area, in the arid rift valley of the Dead Sea shore. These rocky ramps were formed when, in order to enable planting of tropical fruits, stones and small rocks were cleared to the border of the agricultural areas. These ramps provide an excellent shelter for the hyraxes, which tend to live and forage along them. The natural vegetation of this region is dominated by Sudanian trees and bushes that constitute an important food source for the hyraxes. The observation site was a section of a rocky ramp bounded by a large bush of Salvadora persica $(4 \times$ $4 \times 15 \mathrm{~m}$ ). A colony of hyraxes inhabited this bush as a sleeping site from which they emerged for daily activity on the ramp and to forage on the adjacent plains (Figure 2). The ramp was made from randomly scattered stones and rocks in a wide variety of sizes and shapes, forming a heterogeneous habitat in terms of physical features such as exposure to sun or wind. We estimated that about 50 hyraxes inhabited this site.

The cage was $6 \times 2.7 \times 2.8 \mathrm{~m}$; a $5 \times 2 \times 1.5 \mathrm{~m}$ rocky ramp like those in the natural habitat was constructed inside the cages. This ramp had 44 mid-size rocks arranges in eight rows. A shelter box with free access was located next to the ramp, enabling the hyraxes to avoid the ramp at all times. On the basis of previous experience (Mendelssohn, 1965), 1 adult male and 9 adult females were housed in the cage.

\section{Procedure}

Hyraxes were videotaped from a hide with a camcorder (Sony $\mathrm{Hi} 8 \mathrm{CCD} / \mathrm{V} 700 \mathrm{E}$ ) and a zoom lens. Hyraxes were trapped and the fur of each individual was marked with human hair colors (WELLA, Bolondor powder, and Welloxon normal $9 \%$ cream). Animals were retrapped throughout the observation period so that their markings could be renewed as the hair grew. Forty-four individuals were trapped and marked in the wild, several of which were not seen again, probably because of predation or migration. Since repetitive observations of the same individuals were not guaranteed in the wild, additional observations were conducted on 10 caged hyraxes that were marked individually.

Observations in the wild extended over a 1-year period, with 24 days of continuous observations every other week. During the summer (average temperature $39^{\circ} \mathrm{C}$ ), observations were conducted only every $3 \mathrm{rd}$ week since the hyraxes minimized their activity at this time. Observations in captivity extended over 5 months (AugustDecember), with one or two weekly evening observations of $3 \mathrm{~h}$ each. The results are based on video records of $120 \mathrm{~h}$ in the wild and $100 \mathrm{~h}$ in captivity.

\section{Data Collection}

Behavioral analysis was based on scoring the places at which the hyraxes stopped and the sequence of movements they performed during each stop. The rationale for the spatiotemporal separation of motor behavior into bouts of locomotion and stops is available elsewhere (Eilam, Clements, \& Szechtman, 1991; Eilam \& Golani, 1989, 1990, 1994; Golani, Benjamini, \& Eilam, 1993; Szechtman et al., 1994). Since during the bouts of locomotion the hyraxes can perform only small-amplitude lateral or vertical movements, their motor behavior may be described by the different stopping places and by the movements they display during these nonlocomoting periods.

Synchronized VITC and LTC time codes were recorded on the videotapes (Telcom Research, Burlington, Canada). These time codes allowed accurate identification of each frame of the videotape and were read by a computer and custom program that allowed the computer keyboard to function as a real-time event marker at any playback speed. A specific computer key was assigned to each rock or stone in the habitat, and whenever a hyrax stopped at such a place, the time, the name of the stone, the name of the hyrax, and any other desired details were recorded in a database.

In the first playback of all video records, stops of the different hyraxes on the different stones were recorded. Stones (stopping places) were then ranked from most to least frequently visited, and four of the most visited stones were selected for further analysis. For each visit of a hyrax to each of these stones, the following information was scored:

Arriving and leaving places. The stone the hyrax left before arriving at the visited place, and the stone to which it went after leaving the visited place.

Direction of arrival and departure. Directions of arrival and departure of the scored stone were defined in successive clockwise ranges of $45^{\circ}$ marked $0,1,2, \ldots$, with all zero directions aligned to the west. This procedure enabled the description of each place in relation to the environment and allowed the observer to change his location in relation to the ramp when needed.

Behavior on the stone. Since the majority of visits involved crouching or sitting, the description of the behavior during a visit to a stone was divided into three sections: (1) movements from arrival until crouching; (2) posture of crouching; and (3) movements from standing up until stepping down from the stone. Hyraxes rarely displayed vertical movements. Consequently, vertical movements were not scored after their negligible performance was confirmed throughout the video records. By definition, no forward progression was possible during a stop. Consequently, only lateral 
movements were recorded. Lateral movements were described separately for the head and the trunk. Each movement was assigned by its initiation and its direction (clockwise or counterclockwise). Additional scoring of the amplitudes of lateral movements was not included in the following results.

In addition to the above information, information was recorded on the behavior of hyraxes in general (e.g., activity hours, activity range, social interactions, etc.).

\section{Data Analysis}

A chi-square test was employed to compare data with a uniform model. Another test was designed to assess whether high frequency of stops at specific places could have occurred at random. In this statistical procedure, the different stones were ranked from high to low according to the number of visits scored. The number of stops on the first-ranked stone was compared to the first-ranked values extracted from Minitab software for a random Poisson distribution with the same mean and the same number of observations. This procedure was repeated 300 times for each rankordered stone. If the computed values were smaller than the observed value for more than $95 \%$ of the 300 calculated values, it was assumed that the observed number was statistically higher than the value that could have been obtained at random according to a Poissonian model. For instance, if the observed value was bigger than 297 of the 300 randomly extracted values and smaller than
3 , then $p=.01(3 / 300)$. This procedure was repeated independently for each rank-ordered place and for each individual hyrax.

\section{RESULTS}

\section{Preference to Stop on Specific Stones}

During a year of field observations, 2,118 stops of hyraxes on rocks or stones were observed. These stops took place on only 138 out of the hundreds of rocks and stones in the observation area. Calculation of the distribution of the stops over the 138 stones (Figure 1) revealed a tendency to stop on only a few stones. Indeed, $50 \%$ of the stops were on only 8 stones, and $80 \%$ were on only 32 of the 138 stones on which stops took place. In the caged hyraxes, 959 stops were observed on 35 out of the 44 stones; $50 \%$ and $80 \%$ of these stops were made on only 4 and 13 stones, respectively. Thus, the majority of the hyraxes' stops either in the wild or in captivity was restricted to only a few stones. The trend obtained for the whole population of hyraxes was also evident for individual animals. Indeed, $50 \%$ of individuals' stops occurred on an average of 2 stones in both the wild and in

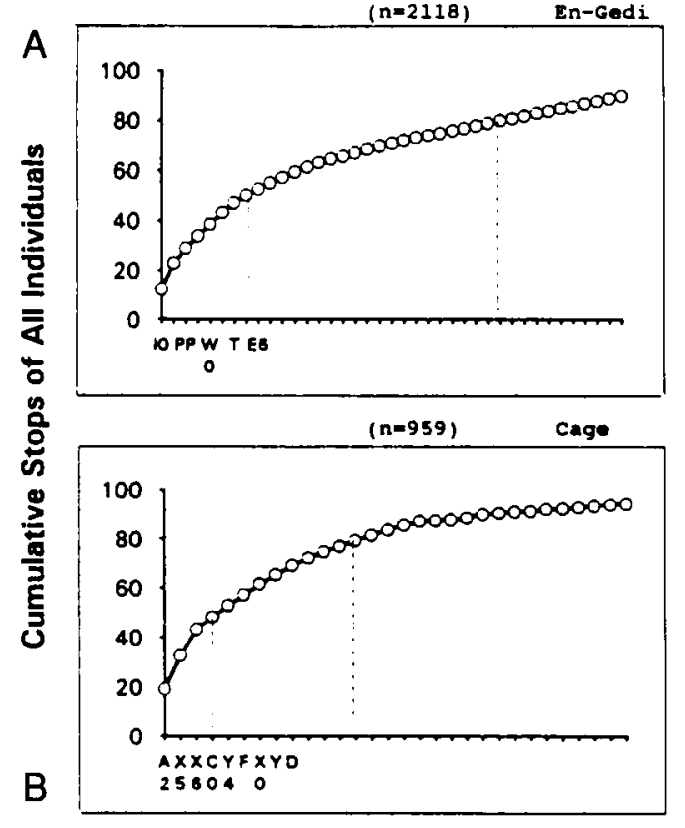

Name of Stone

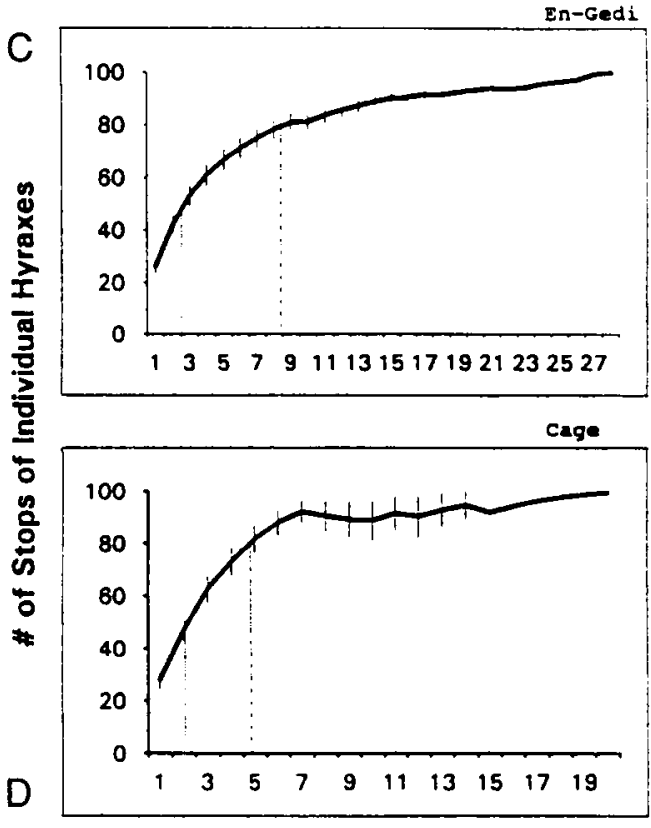

Rank-Order of Stone

Figure 1. A relative cumulative distribution of the stops of all hyraxes in En-Gedi (A) and in the cage (B). Stops of all individuals on a specific stone were pooled together. Stones were then sorted according to the total number of stops $(x-$ axis), and presented by the relative cumulative percentage of the total stops on all stones. Dotted vertical lines indicate $50 \%$ and $80 \%$ of the stops; the intersection between the dotted lines and $x$-axis shows the number of stones constituting $50 \%$ and $80 \%$ of the stops. Labels of the most frequently visited stones are indicated on the $x$-axis. The preference to stop on a few specific stones was significant $(p<.0001$, chi-square test) in both the wild (En-Gedi) and caged populations. Simulating a Poissonian model for the number of stops on each stone (see Method section) revealed that the number of stops on the first 17 stones in En-Gedi and the first 10 stones in the cage was significantly higher $(p<.001)$ than would be expected on the basis of Poisson distribution. The mean nelative distribution of stops in individual hyraxes is shown in $C$ (En-Gedi) and D (cage), to illustrate that the trend seen in the cumulative representation (A and B) was also apparent in individuals and is not a bias imposed by a few individuals. For each hyrax, stones were rank ordered according to the number of stops (regardless of the identity of the stone). The mean relative value $( \pm S E M s)$ for each rank was then calculated and is presented in $C$ and $D$. 
Table 1

Rank Order of Stopping for Individual Hyraxes on Specific Stones

\begin{tabular}{|c|c|c|c|c|c|c|c|c|c|c|c|c|c|}
\hline \multirow[b]{2}{*}{ Stone Name } & \multicolumn{12}{|c|}{ Rank Order of Stones } & \multirow[b]{2}{*}{13} \\
\hline & 1 & 2 & 3 & 4 & 5 & 6 & 7 & 8 & 9 & 10 & 11 & 12 & \\
\hline A2 & 5 & 2 & 2 & 1 & & & & & & & & & \\
\hline $\mathrm{X} 5$ & 3 & 3 & 1 & 1 & 1 & & & & & & & & \\
\hline $\mathrm{X} 6$ & & 3 & 5 & & & 1 & 1 & & & & & 1 & \\
\hline $\mathrm{CO}$ & & & & 2 & 1 & 2 & & 1 & & & 1 & & \\
\hline Y4 & 1 & & & & 1 & 1 & & & & 1 & & & 1 \\
\hline $\mathrm{F}$ & & & & 1 & 1 & 1 & & 1 & 1 & 2 & & 1 & \\
\hline $\mathrm{X} 0$ & & & & 2 & 2 & & 1 & & & & & & \\
\hline Y & & 1 & 1 & 1 & & & 1 & & 1 & 1 & & & \\
\hline D & & & & 1 & & & 1 & 1 & & & 1 & 1 & \\
\hline G & & & & & & & & 1 & 1 & & 2 & 1 & 2 \\
\hline $\mathrm{PO}$ & & & & 1 & & & & 1 & & & & & 1 \\
\hline $\mathbf{M}$ & & 1 & & & & 1 & 2 & 1 & 1 & & 1 & & \\
\hline Y0 & 1 & & & & & & & & 3 & 1 & & & \\
\hline $\mathrm{N}$ & & & & & 1 & & 2 & 1 & & 1 & 1 & & 1 \\
\hline B & & & & & & 1 & & & 1 & 2 & & & \\
\hline K4 & & & & & 1 & 1 & & & & & & 1 & 1 \\
\hline$P$ & & & & & & & & 1 & & & 1 & & 1 \\
\hline I0 & & & & & & 1 & & & & & & & \\
\hline B0 & & & & & & & 1 & & & & & & 1 \\
\hline $\mathrm{U}$ & & & & & 1 & & & 1 & & & & 1 & \\
\hline K & & & & & & & & & & & & 1 & \\
\hline P5 & & & & & & & & & & 1 & & & \\
\hline XX6 & & & & & & & & & 2 & & & & \\
\hline G0 & & & & 1 & & & & & & & & & \\
\hline$X$ & & & & & & & & & & & & 1 & \\
\hline P4 & & & & & & 1 & & & & & & & \\
\hline U4 & & & & & & & 1 & & & & & & \\
\hline
\end{tabular}

\begin{tabular}{cccccccccccccc}
$\begin{array}{c}\text { No. stones } \\
\text { in a rank }\end{array}$ & 4 & 5 & 5 & 8 & 9 & 8 & 8 & 9 & 7 & 7 & 7 & 8 & 7 \\
\hline
\end{tabular}

Note-Columns describe the rank order of stops; column 1 stands for the most visited stone, column 2 for the second, and so on. Rows describe specific stones, as labeled in the left-hand column. Numerals in table represent the number of hyraxes for which that stone was in the specific rank. For instance, Stone A2 was ranked first (most frequently visited) for 5 hyraxes, ranked second for another 2 hyraxes, third for another 2 hyraxes, and fourth for 1 hyrax. Bottom row summarizes how many stones constitute each rank. For instance, in all hyraxes, only four stones (A2, $\mathrm{X} 5, \mathrm{Y} 4$, and $\mathrm{Y} 0$ ) were ranked first; five were ranked second, and so on. As shown, the higher values in the table converge at the top left region, indicating that the hyraxes tended to stop frequently on only the same few stones. Variability, on the other hand, reflects individual preference.

captivity; $80 \%$ of the stops occurred on 8 and 5 stones, respectively. Therefore, each hyrax displayed the majority of its stops on only a few specific stones.

Table 1 illustrates the relationships among the most frequently visited places (stones) of different hyraxes. As shown, different individuals tended to stop on the same few stones, yet there was also a certain amount of variation. This indicates that the preference to stop on the same specific stones was not solely dictated by the physical structure of the environment, but rather, included a component of individual preference.

Figure 2 describes the spatial location of the preferred stones in the observation area. As shown, the eight stones that constituted $50 \%$ of the stops in the wild were arranged in four clusters at distances of $5 \mathrm{~m}$. The most frequently visited cluster was at the highest region of the rock ramp. The second was the closest to the home bush. Each of the remaining stones in this ramp constituted less than $2.5 \%$ of the stops; these were spread around the whole observation area.

\section{Arrival and Departure From Stones}

Four of the most frequently visited stones in the wild (one from each cluster) and the three most frequently visited stones in captivity were chosen for further analyses. Of the many adjacent stones that surround each such stone, there were four stones from which hyraxes arrived in $80 \%$ of the visits to that stone. For each preferred stone, there were typically one or two directions from which most arrivals occurred, and one or two directions toward which all departures occurred (Figure 3).

The preference for directions and places of arrival and departure for specific stones obtained in the pooled data was also evident in individual hyraxes. This is illustrated in Table 2 by the directions of arrival and departure of different hyraxes to the same stone. As shown, 6 hyraxes that were observed on this stone demonstrated a tendency to arrive from the same place, but differed in terms of the places they went after leaving the stone. Again, the similarities and the variances in the specific locations and directions of arrival and departure illustrate that the 

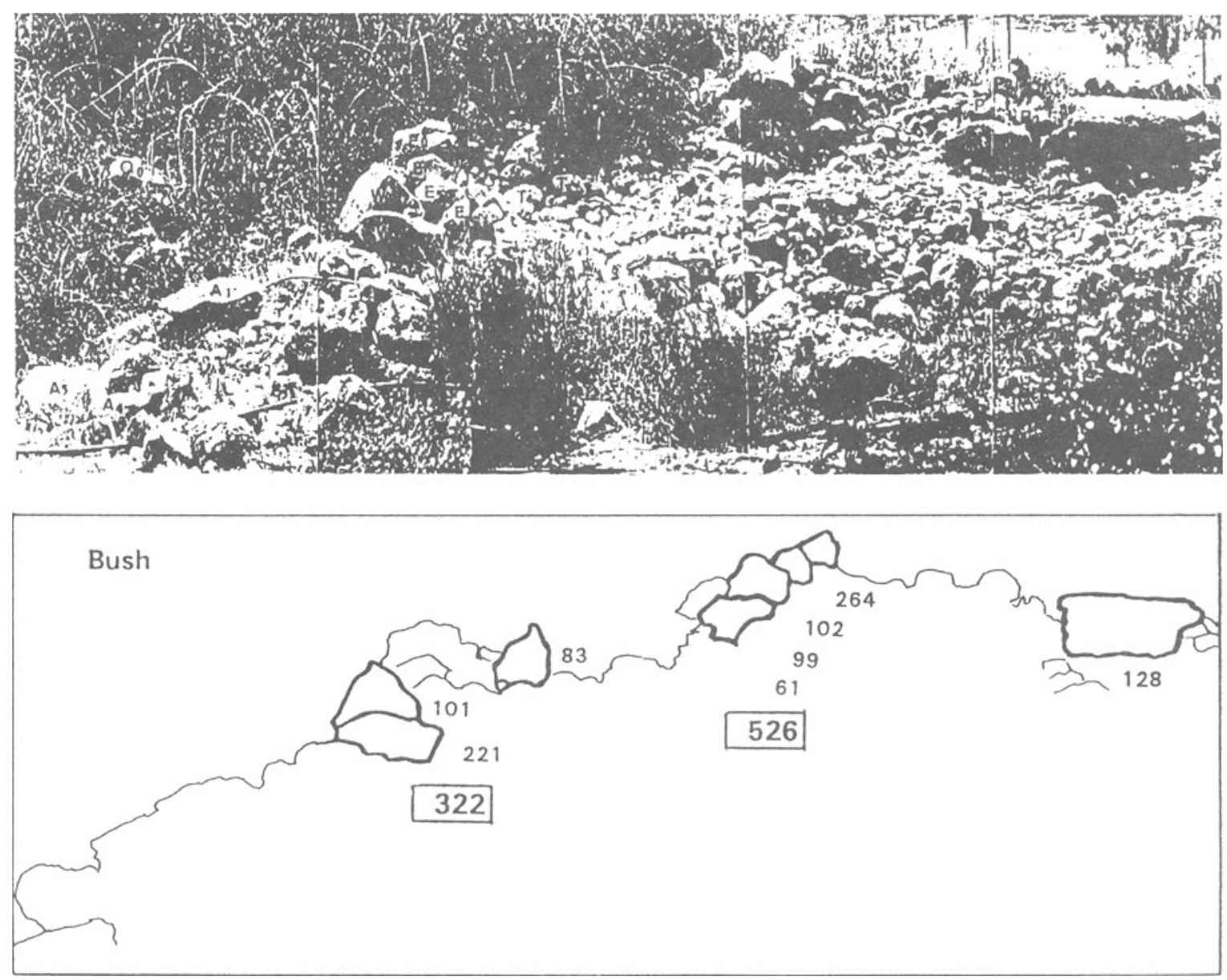

Figure 2. The region of the rock ramp that includes the most frequently visited stones. The bush that functions as the shelter and the "home" of the hyraxes is at the top left comer. An enlarged copy of this figure with the labels of the stones (e.g., Stone A5 at the left bottom corner) was used to specify the stone on which stopping occurred. The most frequently visited eight stones are depicted by heavy lines in the bottom panel. As shown, these eight stones were arranged in four clusters. Two adjacent stones (labeled W0 and W1) together constituted 322 of the 2,118 observed stops (left). On another single stone ( $T$ ), 83 stops were observed. A chuster of four adjacent stones (I0, I7, U0, and $U$ ) constituted 526 stops, and on another stone (PP), 128 stops were observed. Together, these four clusters constituted more than $\mathbf{5 0} \%$ of the stops filmed during the year of observations. As shown, stones were flat (PP) or tapered (W0), at the top of the ramp (10) or at the bottom (W1), in the sunlight (I0) or in the shade (U), and close to the bush (W0) or far from it (PP). Further analyses of behavior included one stone from each cluster.

general preference displayed by the hyraxes was not merely the result of the physical structure of the environment, but also included a degree of individual choice.

\section{Behavior on the Stone}

The duration of a stop on a stone could range from several seconds to several hours. However, regardless of duration, hyraxes tended to sit or crouch during the majority of stops. Figure 4 describes the postures that were observed during stops on stones and the incidence of each such posture in the wild and in captivity. As shown, less than $20 \%$ of the stops did not consist of a sitting, lying, or crouching posture.

As indicated in the Method section, the behavior of a hyrax during a visit to a stone was divided into three parts: (1) behavior from arrival until sitting or crouching;
(2) posture of sitting or crouching; and (3) behavior from standing up until leaving the stone. The first and last of these sections were relatively short in duration. Indeed, upon arrival at a stone, the hyraxes performed only few (if any) lateral movements of the head and torso, and then sat or crouched. Similarly, they performed only a few lateral movements before leaving a stone (Figure 5).

\section{DISCUSSION}

Daily activity in the rock hyraxes consists of motor routines that make their behavior highly predictable: Before leaving their home bush, they climb to the external branches of the bush and then descend through a few fixed locations ("doors") for activity on the adjacent rocky ramp. On this ramp, they tend to stop frequently 


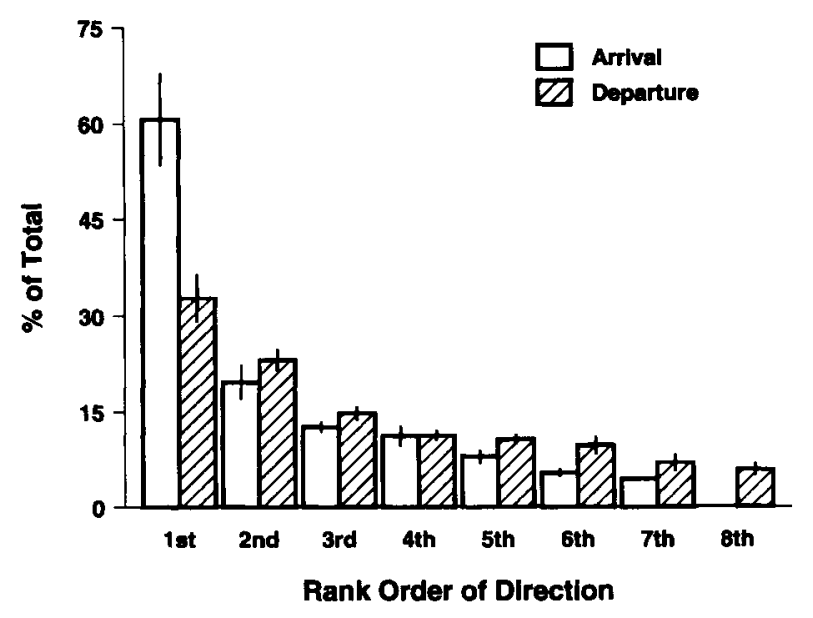

Figure 3. Preference in directions of arrival at $(n=134)$ and departure from $(n=142)$ the four stones was analyzed in detail. The mean $( \pm S E M)$ proportion of the eight possible directions for arrival (open bars) and for departure (striped bars) is presented for each rank order. Comparison of these proportions of directions with an assumed equal proportion revealed a significant difference $(p<.01$ for arrival and for departure, chi-square). Consequently, the proportion was higher in some directions and lower in others, revealing a preference for some directions over others.

on the same few stones, where they sit, lie, or crouch in a few typical postures. In arriving at and leaving these stones, hyraxes have fixed routines: They arrive at the stones in preferred directions from preferred places, and before or after crouching they typically execute not more than one lateral movement of the head and/or the torso. These routines were found in both the wild and caged animals.

Activity of hyraxes in the wild is concentrated in a core area and its close vicinity, where they spend about $95 \%$ of the time crouching and sitting in a few fixed places (Fourie \& Perrin, 1987; Hoeck et al., 1982; Sale, 1970). In the present study, the core area was the bush and the adjacent ramp. Core areas have also been described in other hyrax species (Hoeck et al., 1982), and in other mammalian species, including lagomorphs, primates, rodents, ruminants, and carnivores (Delany, 1982; Jungius, 1971; Kauhala, Helle, \& Taskinen, 1993). Our observations of the activity of the hyraxes in this core area revealed morning and afternoon periods of activity; both periods start when hyraxes climb to the external branches of the bush and then leave the bush to forage. A similar morning routine was described in a previous study, suggesting that rock hyraxes need to bask before they emerge for activity in order to elevate their body temperature, which is relatively low during the night (McNairn \& Fairall, 1984). Although this explanation is applicable for the present morning observations, it is not applicable to the preservation of the same routine in afternoon activity, when the bush area is in the shade. Nevertheless, if we ignore the functional interpretation, morning and afternoon activity share a similar behavioral routine.
The activity of hyraxes is restricted to a few fixed spatial locales. There appear to be only a few locations through which the hyraxes move from the bush to the ramp or vice versa, and they tend to stop on only a few of the hundreds of stones in the observation area. The preferred stones do not necessarily share a common feature: One is high, whereas another is at the bottom of the ramp; one is adjacent to the bush, whereas another is distant; one is exposed to the sun, whereas another is in the shade; and one is flat, whereas another is tapered. Thus, there does not seem to be an obvious "functional" explanation for preferring these few specific stones. To eliminate further the possibility that the behavioral routines in hyraxes are the outcome of the physical structure of the environment, behavioral descriptions were assessed in different crosssections: The behavior of all hyraxes on all stones, the behavior of all hyraxes on a particular stone, and the behavior of a particular hyrax on all stones. These analyses revealed that there exists a relatively rigid motor performance at the level of the individual animal, the particular locale, and in the whole population at the observation site. A preference to display specific acts in specific spatial locales is also evident in other mammalian species. Rhinos (Diceros bicornis, Schenkel \& Schenkel-Hulliger, 1969), deer (Cervus elaphus, Hediger, 1964), antelope (Redunca arundium, Jungius, 1971), and camels (Camelus dromedarius, Schulte \& Klingel, 1991) have fixed crouching and resting places that are preserved for considerable periods. Other species repeatedly visit demarcation sites, where they display a typical ritual of marking by urinating, defecating, or secreting scent materials (see, e.g., Henschel \& Skinner, 1991; C. F. Mason \& MacDonald, 1986; Muller-Schwarze, 1972; Richardson, 1991). These studies, together with the present results, indicate that the

Table 2

Preference for Specific Places of Arrival and Departure for 6 Different Hyraxes for the Same Stone

\begin{tabular}{|c|c|c|c|c|c|}
\hline \multirow{2}{*}{$\begin{array}{l}\text { Stone } \\
\text { Name }\end{array}$} & \multicolumn{5}{|c|}{ Rank Order of Stones } \\
\hline & 1 & 2 & 3 & 4 & 5 \\
\hline \multicolumn{6}{|c|}{ Arrival } \\
\hline $\mathrm{X} 0$ & 6 & & & & \\
\hline $\mathrm{CO}$ & & 3 & & 1 & \\
\hline X6 & & 1 & & 1 & \\
\hline$X$ & & & 1 & & 1 \\
\hline \multirow[t]{2}{*}{$\mathrm{D}$} & & & 2 & & \\
\hline & 6 & 4 & 3 & 2 & 1 \\
\hline \multicolumn{6}{|c|}{ Departure } \\
\hline $\mathrm{X} 6$ & 2 & 2 & 1 & 1 & \\
\hline Xo & 2 & 2 & 1 & 1 & \\
\hline Floor & 1 & 2 & & & 2 \\
\hline$X$ & & & 2 & 1 & 1 \\
\hline \multirow[t]{2}{*}{ D } & & & & 1 & 2 \\
\hline & 5 & 6 & 5 & 5 & 3 \\
\hline
\end{tabular}

Note-Left column provides the names of stones at which the hyraxes arrived or from which they departed. Numerals in the table indicate the number of hyraxes using this rank, and rows 7 and 14 describe the number of hyraxes using this stone at a specific rank. As shown, all hyraxes tended to arrive at the observed stone from the same place $(\mathrm{X} 0)$, but they departed to different stones. 


\section{Postures While on a Stone}
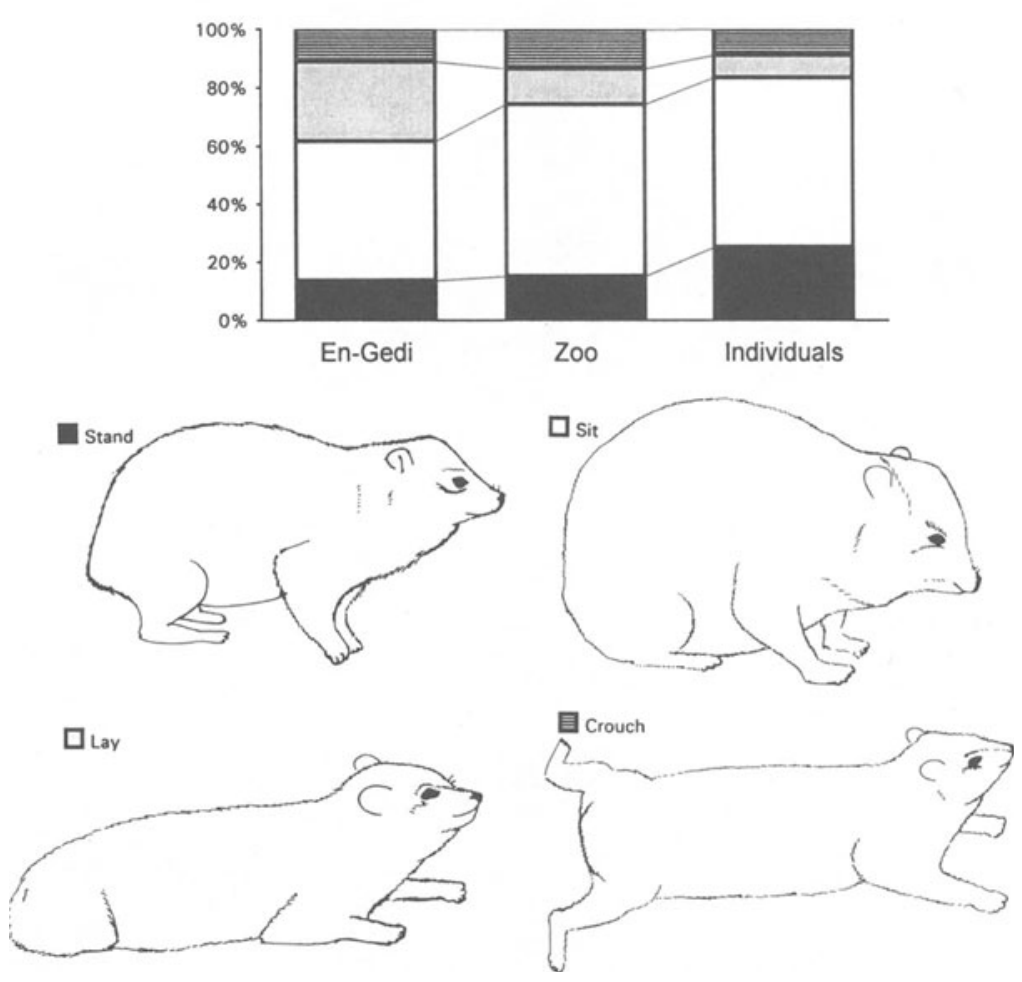

Figure 4. Postures of crouching, lying, sitting, and standing on stones and their mean relative distribution. Postures are illustrated at the bottom of the figure, along with the respective shade of the graphic representation. In Stand, no part of the trunk is in contact with the substrate. In Sit, only the pelvis is in contact with the ground. In Lie, the entire trunk (excluding head and neck) is in contact with the substrate, and hind legs are flexed underneath the trunk. In Crouch, the entire trunk (and sometimes the head and neck) is in contact with the ground, and the hind legs are extended backward and sideways. The relative distribution is represented as the mean percentage of stops of all hyraxes on the different stones for En-Gedi $(n=565)$ and caged (zoo, $n=257)$ populations. The data for individuals represent the mean performance of each posture of 10 individual hyraxes on 379 stops on the same specific stone. As shown, hyraxes tended to sit, lie, or crouch when they stopped on a stone, and remained standing at less than $20 \%$ of the stops.

display of specific acts in specific places in animal behavior does not necessarily merely reflect the structure of the environment, but may also include an element of individual choice or preference.

\section{Rigidity in Motor Performance as a Strategy for Simplification}

Exaggerated performance of rigid motor routines, or stereotypy, is frequently seen in caged animals or animals under the influence of psychoactive drugs. G. J. Mason (1991) suggested that stereotypies may have something in common with normal behavior patterns since repetitive performance of a behavior pattern is not unique to stereotypies. Nevertheless, repetitive performance of a behavior pattern or action in a particular time and place is indeed the conspicuous and indisputable characteristic of stereotypy. If inflexible motor routines, such as the repeated visits of the hyraxes to the same few places, are considered "stereotyped performance," the mechanisms underlying the development of stereotypy may cast light on the possible benefits that hyraxes may gain from their unvarying behavior.

In a study of transition from normal locomotion to drug-induced locomotor stereotypy in wild rats, it was proposed that the drug amphetamine induces a gradual reduction in the number of different stopping places and an increase in the rigidity of the sequencing of stops (i.e., stereotyped rats tend to stop in the same places and in the same order; Eilam \& Golani, 1994). Thus, locomotor behavior becomes consolidated into "packages" or "chunks," each consisting of the same few places where the rat stops in a fixed order, and the rat loses the free and direct access to other places in the environment that is characteristic of normal behavior. Eilam and Golani (1994) also suggested that this consolidation of locomotor behavior is reminiscent of similar processes of the chunking that takes place during learning in humans and in the formation of packages in bird song, such chunk- 


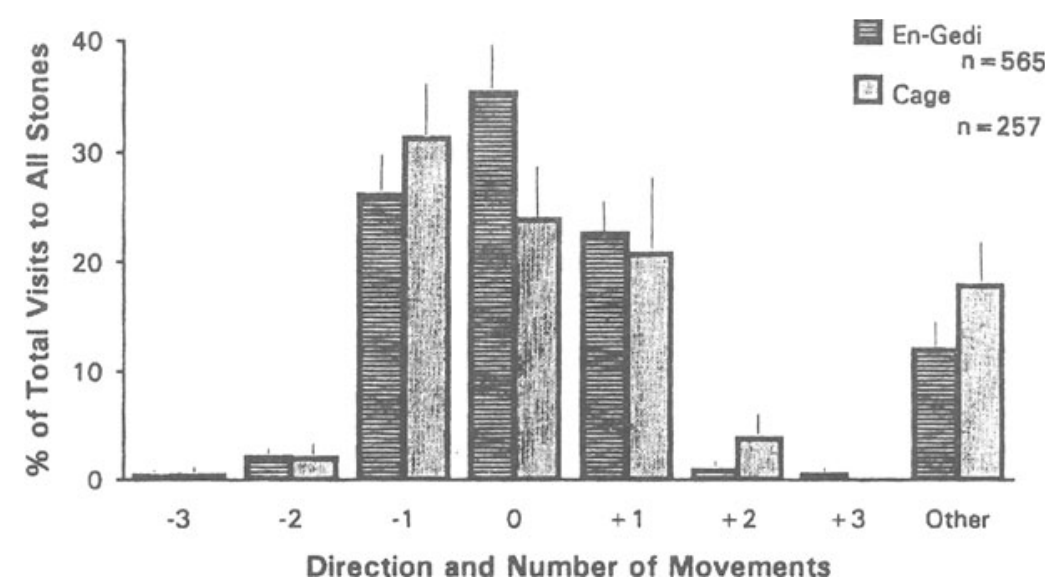

Figure 5. Relative proportion of lateral movements of the head during visits at (stops at)
stones in En-Gedi and in the cage. The $x$-axis describes the number and direction of lateral
head movements; + , clockwise movements; - , counterclockwise movements; 0 , no lateral
movement; 1 , a single lateral movement of the head; 2 , two successive lateral movements in
the same direction. The amplitude was not considered in all categories, and movements
were onty counted. Since hyraxes rarely perform more than three movements in the same
direction or switching in movement from side to side, these incidents were grouped under
"Other." The $y$-axis shows the mean percentage ( $(S E M)$ of stops in which each category
for number of movements was performed either at arrival at or before exiting the stone. As
shown, the majority of stops included not more than one lateral movement of the head. $A$
similar trend was evident in the lateral movements of the torso, where more than $90 \%$ of
the stops included not more than a single lateral movement of the torso (data not shown).

ing serves as a strategy for coping with an increasing load on information processing capacity. Therefore, the establishment of packages under amphetamine was proposed as a hypothetical mechanism for coping with a drug-induced reduction in information processing capacity (Eilam \& Golani, 1994). Fentress (1976) proposed that in normal animals, minimizing involvement of information processing systems enables the animal to direct its attention elsewhere and perform the action pattern more rapidly. Applying this model to the present results, one might argue that displaying behavioral rigidity, such as the preference to stop in fixed places or to approach specific places in specific directions, may facilitate faster performance or may require less attention, thus enabling the hyraxes to direct more attention to other aspects of the environment, such as the presence of potential predators. For instance, fixed routes enable the hyrax to return in a fast, "automated," fashion to a shelter. Of course predators may also take advantage of these fixed motor routines. Indeed, observations in En-Gedi revealed that leopards (Panthera pardus) display "gambling" jumps to rocky ramps where hyraxes tend to crouch. It seems that the leopards execute this predatory pattern on the basis of previous "knowledge" that hyraxes tend to crouch on that rock, regardless of the actual presence of hyraxes at the specific moment of jumping (G. Ilani, personal communication, 1986).

\section{A Parallel Between Stereotypy and Normal Motor Routines?}

Thus far we have been approaching the interpretation of motor routines from a functional perspective; we now shift the focus to performance. Behavioral rigidity in normal motor routines and in stereotypies raises the question of the extent to which these behaviors are analogous in structure and/or mechanism. Stereotypy is defined as unvarying, repetitive behavior patterns that have no obvious function (Fox, 1965; Immelmann \& Beer, 1989; Odberg, 1978). This definition expresses the two central facets of stereotypy: purposelessness and repetitiveness. "Purposelessness" is an ambiguous characteristic, however-hard to assess in animals. Moreover, several researchers have suggested that stereotyped performance per se may result in an indirect benefit such as relief of anxiety in animal stereotypy (Dantzer \& Mormède, 1983; Hutt \& Hutt, 1965; G. J. Mason, 1991, 1993; Wechsler, 1991) and in compulsive behavior in humans (Rapoport, 1989). Regardless of the questions surrounding the status of purposelessness, unvarying and incessant repetitive performance is the conspicuous feature of stereotypy. To evaluate the rate of repetition in the hyraxes as compared to that in stereotypy, we compared the stopping behavior of the hyraxes (present data) with the stopping behavior in normal and amphetamine-treated wild rats (data from Eilam, 1987; Eilam \& Golani, 1994). It should be noted that rats treated with $5-\mathrm{mg} / \mathrm{kg}$ amphetamine are highly stereotyped in their locomotion, traveling along fixed routes and stopping in fixed places in a fixed order so that their behavior is entirely predictable (Eilam \& Golani, 1994). As shown in Figure 6, the rate of stopping of the caged and free-living hyraxes was very close to that of the amphetamine-treated wild rats. Thus, when considered in terms of stopping places, the behavior of hyraxes falls in between normal behav- 
ior and the most stereotyped stopping behavior of amphetamine-treated wild rats.

This similarity in the rate of repetition in what seems to be stereotyped performance may be explained by considering activity in reference to time and space (Fentress, 1992; Gallistel, 1989). In other words, behavioral performance is evaluated through three variables: (1) the level of activity; (2) the space (locale) available for performance; and (3) the time of endurance. Affecting at least one of these variables may induce repetitive "stereotyped" performance, as illustrated in the following examples:

Activity. In drug-induced stereotypy, time and space are held constant, but activity is increased. Indeed, stereotyped rats are typically hyperactive, but they are tested in the same space and time frame used for their normal, less active, performance. As a result, the rate of repetition of activity in specific places is increased, and stereotyped performance is evident (Eilam et al., 1991; Eilam \& Golani, 1989, 1990; Geyer, 1982; Mueller, Kunko, Whiteside, \& Haskett, 1989; Szechtman et al., 1994).

Space. In cage stereotypies, the space available for behavioral performance shrinks relative to that in the natural home range so that even a normal level of activity has to be executed within a confined environment. For instance, martens (Martes martes) display demarcation

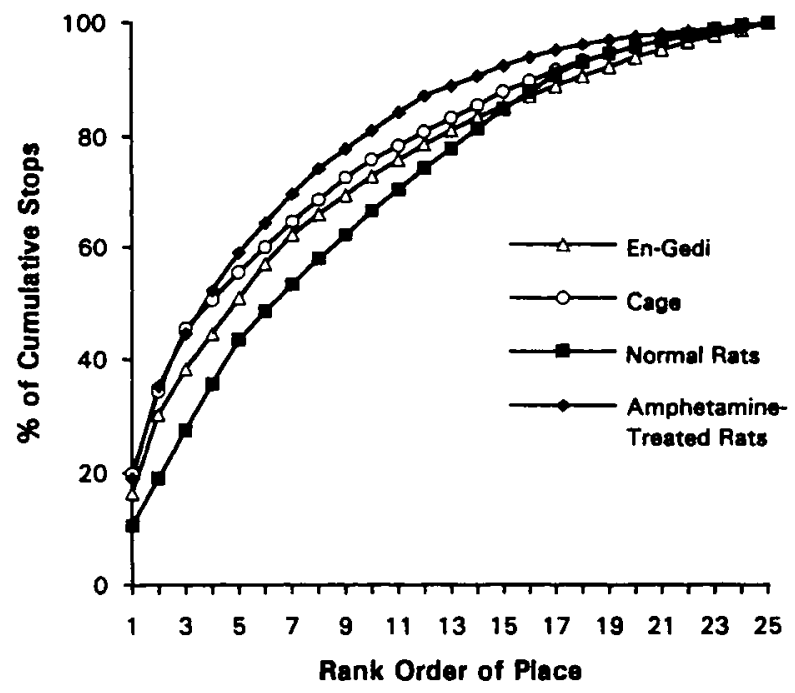

Figure 6. Cumulative proportion (\%) of stops on stones in hyraxes and locations in the open field in wild rats. Data for each group are for the 25 most frequently visited places. (The effect of additional places in the hyraxes is negtigible, since $80 \%$ of their stops were paid to only a few places; see Figure 1.) Data for both normal and amphetaminetreated rats are based on Eilam (1987) and were sconed during a 1-h observation of each rat. Rats treated with $5-\mathrm{mg} / \mathrm{kg}$ amphetamine (upper line; $n=4,229$ stops) were very stereotyped, locomoting along a fixed rigid route and stopping repeatedly in the same few places (Eilam \& Golani, 1994). The lower line shows the distribution of stops $(n=1,339)$ in the same rats when they were tested without amphetamine. As shown, stopping behavior of the hyraxes in the zoo (cage; $n=$ 913 stops) and in the wild (En-Gedi; $n=1,656$ stops) falls in between the two lines of the rats, with similarity in high ranks. For instance, the distribution in amphetamine-treated rats and caged hyraxes overlaps for more than $50 \%$ of the stops. in specific places, and whenever they pass through such a place, they stop and mark it. In nature, when inhabiting a large range, the marten returns to the same demarcation place every other day, and the rate of repetition of marking per place is relatively low. In captivity, however, a marten bumps into the marking place frequently because of the limited space, and a high frequency of demarcation behavior in the same place is evident (Hediger, 1964). Indeed, stereotypy is a typical response of animals to restricted environment (Morris, 1964); consequently, such stereotypy is particularly severe in caged animals that naturally inhabit a large home range or territory.

Time. When space and activity are maintained at normal levels, behavior seems "normal" and not "stereotyped." However, if observation time is extended, the accumulation of activity in a specific space (i.e., "place") highlights motor routines through the higher cumulative rate of performance. Indeed, observation of the hyraxes for an entire year in the present study revealed a rate of repetition similar to that measured in hyperactive stereotyped amphetamine-treated rats during $1 \mathrm{~h}$ of observation.

The discussion above does not answer the question of what stereotypy is. Neither does it interpret the absence of obvious reward for a perseverative performance. However, it may highlight the natural and normal behavioral foundation from which stereotyped behavior is derived: Stereotypy stems from normal behavior under physiological or physical changes that result in exaggerated repetition of behavioral patterns in specific times and places.

As noted, the exaggerated rate of performance (repetition) has been proposed as the central feature of stereotypy. Robbins (1977) claimed that we describe behavior as stereotyped when intuitively and subjectively we can fix the limits of a repetitive bout of behavior. This, in itself, does not resolve the difficulty in dividing the continuous flow of behavior into discrete categories, normal or stereotyped. Indeed, the border between normal and stereotyped behavior seems arbitrary and blurred. For instance, in a study of stereotypy in the red-backed vole (Clethrionomys glareolus), a threshold of 10 repetitions was employed to discriminate stereotypy from normal behavior (Cooper \& Nicol, 1991). According to this criterion, 9 repetitions is judged as "normal," but 10 is judged as "stereotyped" behavior. Moreover, the similarity between normal and stereotyped behavior does not resolve the question of whether stereotypy implies "abnormality." These topics are thoroughly discussed by G. J. Mason $(1991,1993)$. However, the repetitive motor routines in hyraxes suggest a possible normal foundation for stereotypy.

\section{Shrinkage of the Attended Space as a Unifying Concept}

The initiatives for the different types of repetitive motor performance described so far, as well as the underlying mechanisms that control this performance, may vary. However, at the conceptual level, the different types 
of repetitive performance may be ascribed to a shrinkage of the attended space. Repetitive behavior stems from shrinkage of the attended space in drug-induced behavior (Oades, Rea, \& Taghzonbi, 1985), from physical confinement of locomotory space in caged animals, and from the need to direct attention to other environmental factors in normal animals. However, whereas in normal animals the repetitive performance of the same task involves in reduced attention, in drugged animals, capacity for information processing is generally reduced (Cooper \& Nicol, 1991; Fentress, 1976), and not simply reduced relative to reduced spatial parameters. Thus, regardless of the underlying "functional" mechanism, stereotypy and normal behavior may constitute the same acts and movements, but may differ in terms of the rate of performance in specific times and places.

\section{Motor Routines and Compulsive Behavior}

Fixed motor routines formed the cornerstone of zoology, and particularly of classic ethology. Darwin (see Hediger, 1964) described how turtles have one typical behavior on their way to drink, and another typical behavior on their return, with both behaviors executed along a fixed route. Lorenz (1966) described how motor habits of water shrews develop into a custom that the shrews cannot break, despite conflicting sensory information: In one of their paths, the shrews became habituated to jumping over a stone. After the stone was removed, the shrews continued to jump repeatedly as if the stone had still been there. Lorenz (1966) also described fixed motor routines in his goose Martina, or in himself while driving in Vienna. In describing these habits, Lorenz wrote: "My examples of animal behavior will remind the psychiatrist and the psychoanalyst of the compulsive repetition of some acts, a symptom of certain type of neurosis" (p. 60). Similarly, many scientists of human compulsive behavior, particularly those using animal models, compared human to nonhuman behavior. An extreme example is Insel (1988), who wrote: "The available analysis of the phenomenology of compulsive rituals pales before elegant observations of analogous behaviors in fish and birds." Indeed, studies of human compulsions generally describe an abundant increase in the rate of performance of normal behavioral patterns, using terms borrowed from ethology, such as "ritualized behavior" (Rapoport, 1990), "displacement activity," and "stereotypy" (Insel, 1988).

Great care, however, should be taken in drawing parallels between obsessive-compulsive disorder (OCD) in human patients and motor routines in animals, since the diagnosis of OCD depends on cognitive symptoms inaccessible in freely moving animals (G. J. Mason \& Turner, 1993). However, a search for parallels in underlying mechanisms in OCDs and animal motor routines may benefit from a consideration of these behaviors strictly at the level of motor performance. In OCD, compulsion is a repetitive purposeful behavioral ritual that is perceived as unnecessary, and performed in a stereotyped fashion. Patients may wash their hands $80-100$ times each day or spend $2-3 \mathrm{~h}$ in the shower. Others may check incessantly whether gas jets or lights have been left on (Rapoport, 1989). Thus, the conspicuous feature of compulsion is the increase in the rate of performance of normal acts (Rapoport, 1989). Indeed, the essence of human compulsions is that the behavioral routine is normal in structure and function, but abnormal in the high rate of performance in a specific time and place. Pitman (1989) suggested that compulsions represent activity of a phylogenetically primitive cortico-striato-pallidal (basal ganglia) habit system, and awareness of the senselessness of the compulsions represents conflicting activity of a more advanced cortico-limbo-diencephalic memory system. Accordingly, in compulsive disorders, the memory system fails to curb the habit system. If motor routines like those described in the hyraxes are considered ingredients of the habit system, they may also have been conceived as the foundation of compulsive behavior. The above-cited parallel between motor routines in the spontaneous behavior of freely moving animals and stereotypies or compulsions was based solely on the level of performance. Yet compulsions seem to differ from normal repetitive routines in that they capture the entire attention of the patient. In normal behavior, motor routines may reduce the attention devoted to performance per se, whereas in compulsions, all the attention is directed to performance. However, attention is not implicit in motor performance as such, and may be assessed only in behavioral paradigms that are designed specifically to measure attention. Moreover, although the motor routines in hyraxes are in a sense "stereotyped," they are ingrained in the flow of daily activity, which is not pathologically constricted. The excessive attention devoted to compulsions in humans is remarkable for the consequential aspects of functionality neglect. In this regard, human compulsions are quite different from the behavior of normal hyraxes, despite being reminiscent at the level of motor performance. It is assumed that human compulsions are based on normal acts (e.g., washing), but further study of the development of motor compulsions is required to assess whether the compulsive rituals develop from preexisiting daily routines such as those described in the hyraxes.

The present results reveal frequent fixed motor routines in the behavior of hyraxes that are executed repeatedly in the same places. Despite the differences between such routines and performance in stereotyped behavior in the motor habits of normal animals and in compulsions of human patients, the similarities may indicate a parallel in the structure and/or the underlying mechanism.

\section{REFERENCES}

CoOper, J. J., \& NiCol, C. J. (1991). Stereotypic behavior affects environmental preference in bank voles Clethrionomys glareolus. Animal Behaviour, 41, 971-977.

DAntzer, R., \& Mormède, P. ( 1983). De-arousal properties of stereotyped behaviour: Evidence from pituitary-adrenal correlates in pigs. Applied Animal Ethology, 10, 233-244.

Delany, M. J. (1982). Mammal ecology. London: Blackie.

EILAM, D, (1987). Exploratory behavior in normal and amphetamine- 
treated wild Norway rats (Rattus norvegicus). Doctoral dissertation, Tel-Aviv University, Ramat-Aviv, Israel.

Eilam, D., Clements, K. V. A., \& Szechtman, H. (1991). Differential effects of D1 and D2 dopamine agonists on stereotyped locomotion. Behavioural Brain Research, 45, 117-124.

EILAM, D., \& GolaNi, I. (1989). Home base behavior of rats (Rattus norvegicus) exploring a novel environment. Behavioural Brain Research, 34, 199-211.

EILAM, D., \& Golan, I. (1990). Home base behavior in amphetaminetreated tame wild rats (Rattus norvegicus). Behavioural Brain Research, 36, 161-170.

EILAM, D., \& Golani, I. (1994). Amphetamine induced stereotypy in rats: Its morphogenesis in locale space from normal exploration. In S. J. Cooper \& C. A. Hendrie (Eds.), Ethology and pharmacology (pp. 241-266). Chichester, U.K.: Wiley.

FENTRESS, J. C. (1976). Dynamic boundaries of patterned behavior: Interaction and self-organization. In P. P. G. Bateson \& R. A. Hinde (Eds.), Growing points in ethology (pp. 135-167). Cambridge: Cambridge University Press.

FENTRESS, J. C. (1992). Emergence of pattern in the development of mammalian movement sequences. Journal of Neurobiology, 23, $1529-1556$.

Fourie, L. J., \& Perrin, M. R. (1987). Social behavior and spatial relationships of the rock hyrax. South Africa Journal of Wildlife Research, 17, 91-98.

Fox, M.W. (1965). Environmental factors influencing stereotyped and allelomimetic behavior in animals. Laboratory Animal Care, 15, 363-370.

Gallistel, C. R. (1989). Animal cognition: The representation of time, space and number. Annual Reviews in Psychology, 40, 155-189.

GEYER, M. A. (1982). Variational and probabilistic aspects of exploratory behavior in space: Four stimulant styles. Psychopharmacology Bulletin, 18, 48-51.

Golani, I., Benjamini, Y., \& Eilam, D. (1993). Stopping behavior: Constraints on exploration in rats (Rattus norvegicus). Behavioural Brain Research, 53, 21-33.

Gorman, M. L., \& Trowbridge, B. J. (1989). The role of odor in the social lives of carnivores. In J. L. Gittleman (Ed.), Carnivore behavior, ecology, and evolution (pp. 57-88). Ithaca, NY: Cornell University Press.

Hediger, H. (1964). Wild animals in captivity. New York: Dover.

HensChel, J. R., \& SKINNER, J. D. (1991). Territorial behavior by a clan of spotted hyenas Crocuta crocuta. Ecology, 88, 223-235.

HoECK, H. N., KLEIN, H., \& HoEcK, P. (1982). Flexible organization in hyrax. Zeitschrift für Tierpsychologie, 59, 265-298.

HutT, C., \& HuTT, S. J. (1965). Effect of environmental complexity on stereotyped behaviors of children. Animal Behaviour, 13, 1-4.

ImmelmanN, K., \& BeER, C. (1989). A dictionary of ethology. Cambridge, MA: Harvard University Press.

INSEl, T. (1988). Obsessive-compulsive disorder: New models. Psychopharmacology Bulletin, 24, 365-369.

JungIUs, H. (1971). The biology and behavior of the reedbuck (Redunca arundinum Boddaert 1785) in the Kruger National Park. Hamburg: Paul Parey.

Kauhala, K., Helle, E., \& Taskinen, K. (1993). Home range of the raccoon dog (Nyctereutes procyonoides) in southern Finland. Journal of Zoology, 231, 95-106.

LEGGE, D., \& BARKER, P. J. (1976). Information and skill. London: Methuen.

LORENZ, K. (1966). On aggression. London: Methuen.

LORENZ, K. (1971). Studies in animals and human behavior (Vol. 2). Cambridge, MA: Harvard University Press.

Mason, C. F., \& Macdonald, S. M. (1986). Otter ecology and conservation (pp. 47-84). New York: Cambridge University Press.

Mason, G. J. (1991). Stereotypies: A critical review. Animal Behaviour, 41, 1015-1037.

MAson, G. J. (1993). Forms of stereotypic behavior. In A. B. Lawrence \& J. Rushen (Eds.), Stereotypic animal behavior: Fundamentals and applications to welfare (pp. 7-40). Wallingford, U.K.: CAB International.

Mason, G. J., \& Turner, M. A. (1993). Mechanisms involved in the development and control of stereotypies. In P. P. G. Bateson, P. H. Klopfer, \& N. S. Thompson (Eds.), Perspectives in ethology: Vol IO. Behavior and evolution (pp. 53-85). New York: Plenum.

MCNaiRn, I. S., \& Fairall, N. (1984). Metabolic rate and body temperature of adult and juvenile hyrax (Procavia capensis). Comparative Biochemistry \& Physiology, 79A, 539-545.

MENDELSSOHN, H. (1965). Breeding the Syrian hyrax. International Zoology Yearbook, 5, 116-125.

Mendelsshon, H., \& Yom-Tov, Y. (1987). Mammals. In A. Alon (Ed.), Plants and animals of the land of Israel (Vol. 7). Tel-Aviv: Ministry of Defense.

MORRIS, D. (1964). The response of animals to a restricted environment. Symposium of the Zoological Society, 13, 99-118.

Mueller, K., Kunko, P. M., Whiteside, D., \& Haskett, C. (1989). Time course of amphetamine-induced stereotypy in an open field. Psychopharmacology, 99, 501-507.

MUlLER-SCHWARZE, D. (1972). Social significance of forehead rubbing in blacktailed deer (Odocoileus columbianus). Animal Behaviour, 20, 788-797.

OAdEs, R. D., ReA, M., \& TAGHzonbi, K. (1985). Modulation of selective processes in learning by neocortical and limbic dopamine: Studies of behavioral strategies. In B. E. Will, P. Schmitt, \& J. C. Dalrymple-Alfords (Eds.), Brain plasticity, learning and memory (pp. 241-251). New York: Plenum.

ODBERG, F. (1978). Abnormal behaviors (stereotypies). In Proceedings of the First World Congress on Ethology Applied to Zootechnics (pp. 475-480). Madrid: Industrias Graficas.

Pitman, R. K. (1989). Animal models of compulsive behavior. Biological Psychiatry, 26, 189-198.

RAPOPORT, J. L. (1989). The biology of obsessions and compulsions. Scientific American, 260, 83-89.

RAPOPORT, J. L. (1990). The waking nightmare: An overview of obsessive compulsive disorder. Journal of Clinical Psychiatry, 51 (Suppl.), 25-28.

RichARDSON, P. K. R. (1991). Territorial significance of scent marking during the non-mating season in the Aardwolf proteles cristatus (Carnivora: Protelidae). Ethology, 87, 9-27.

Robiss, T. W. (1977). A critique on the methods available for measurement of spontaneous motor activity. In L. L. Iversen, S. D Iversen \& S. H. Snyder (Eds.), Handbook of psychopharmacology (Vol. 7, pp. 37-82). New York: Plenum.

RowE-Rowe, D. T. (1992). Survey of South African otters in a freshwater habitat, using sign. South Africa Journal Wildlife Research, 22, 49-55.

SALE, J. B. (1970). The behavior of the resting rock hyrax in relation to its environment. Zoologica Africana, 5, 87-99.

SChenkel, R., \& Schenkel-Hulliger, L. (1969). Ecology and behavior of the black rhinoceros (Diceros bicornis L.). Hamburg: Paul Parey.

Schulte, N., \& KLINGEl, H. (1991). Herd structure, leadership, dominance and site attachment of the camel, Camellus dromedarius. Behaviour, 118, 103-114.

Szechtman, H., Talangbayan, H., Canaran, G., Dal, H., \& EILAM, D. (1994). Dynamics of behavioral sensitization induced by dopamine agonist quinpirole and a proposed central energy control mechanism. Psychopharmacology, 115, 95-104.

TinBERGEN, N. (1951). The social behavior of animals. London: Methuen. YON-UEXKULL, J. (1957). A stroll through the world of animals and men. In C. H. Schiller (Ed.), Instinctive behavior: The development of a modern concept (pp. 5-82). New York: International Universities Press.

WeChSLER, B. (1991). Stereotypies in polar bears. Zoo Biology, 10, 177-188.

\section{APPENDIX \\ Other Regularities in Hyrax Behavior}

"Doors" in the bush. Although the edging of the bush on the rock ramp seemed homogeneous, there were a few specific points through which the hyraxes left the bush for activity on 
the rocks, and through which they returned to the bush after activity. These we termed "doors." Fifty percent of the 493 passes were made through 2 of the 11 doors through which passes were observed, indicating a preference for specific doors over others (chi-square, $p<.001$ ). Thus, there were only a few specific passing points in the seemingly homogeneous border of the bush and the ramp. Moreover, although the hyraxes used only 11 points for passing, there was a preference for using 2 specific points out of these 11 points.

Daily periods of activity. Daily activity in the wild was observed in the morning and the afternoon. Each period of activity started in the same manner: Before leaving the bush, the hyraxes emerged from the inner part of the bush to external branches, where they sat for 30 to 60 minutes. They then descended to the inner branches, and from there left the bush for activity.

Crossing open spaces. Hyraxes crossed the open plateau between the rocky ramps in two ways. First, they crossed as a group. Several hyraxes left one ramp together, and while graz- ing they progressed slowly through the plateau to another rocky ramp. Second, hyraxes departed individually: A hyrax appeared at a specific point on the ramp, stood there for a few minutes, and suddenly darted through the open space to another ramp. Other hyraxes then individually followed the same path and stages of crossing (individual sneaking).

Fighting. During May and June, aggression between individuals increased. Hyraxes with severe wounds in the shoulder or cheek were frequently observed. In an anecdotal observation of a fight between 2 males, the male that dominated the observation area chased another male to the open space, bit it in the shoulder, and then kept dragging it for $15 \mathrm{~min}$ while walking slowly backward. Within a few minutes the bitten hyrax started to bleed. Ultimately it escaped with a large wound in the shoulder - a wound seen in many other hyraxes during these months.

(Manuscript received September 21, 1995; revision accepted for publication March $28,1996$. 